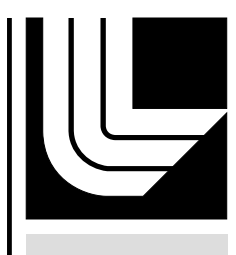

LAW RENCE LIVERMORE N A TIO N A L LABORATORY

NNPP Training - Customer Support Material

C. Gellner, J. Greenfield, L. Placeres

January 24, 2011 
This document was prepared as an account of work sponsored by an agency of the United States government. Neither the United States government nor Lawrence Livermore National Security, LLC, nor any of their employees makes any warranty, expressed or implied, or assumes any legal liability or responsibility for the accuracy, completeness, or usefulness of any information, apparatus, product, or process disclosed, or represents that its use would not infringe privately owned rights. Reference herein to any specific commercial product, process, or service by trade name, trademark, manufacturer, or otherwise does not necessarily constitute or imply its endorsement, recommendation, or favoring by the United States government or Lawrence Livermore National Security, LLC. The views and opinions of authors expressed herein do not necessarily state or reflect those of the United States government or Lawrence Livermore National Security, LLC, and shall not be used for advertising or product endorsement purposes.

This work performed under the auspices of the U.S. Department of Energy by Lawrence Livermore National Laboratory under Contract DE-AC52-07NA27344. 


\title{
NNPP Training Customer Support Material
}

\author{
NARAC \\ Lawrence Livermore National Laboratory \\ Livermore, CA 94551 \\ January $25-27,2011$
}

This work performed under the auspices of the U.S. Department of Energy by Lawrence Livermore National Laboratory under Contract DE-AC52-07NA27344 
Internet Failure 
April 27, 2010

\section{Communications with NARAC Options and failover Checklist}

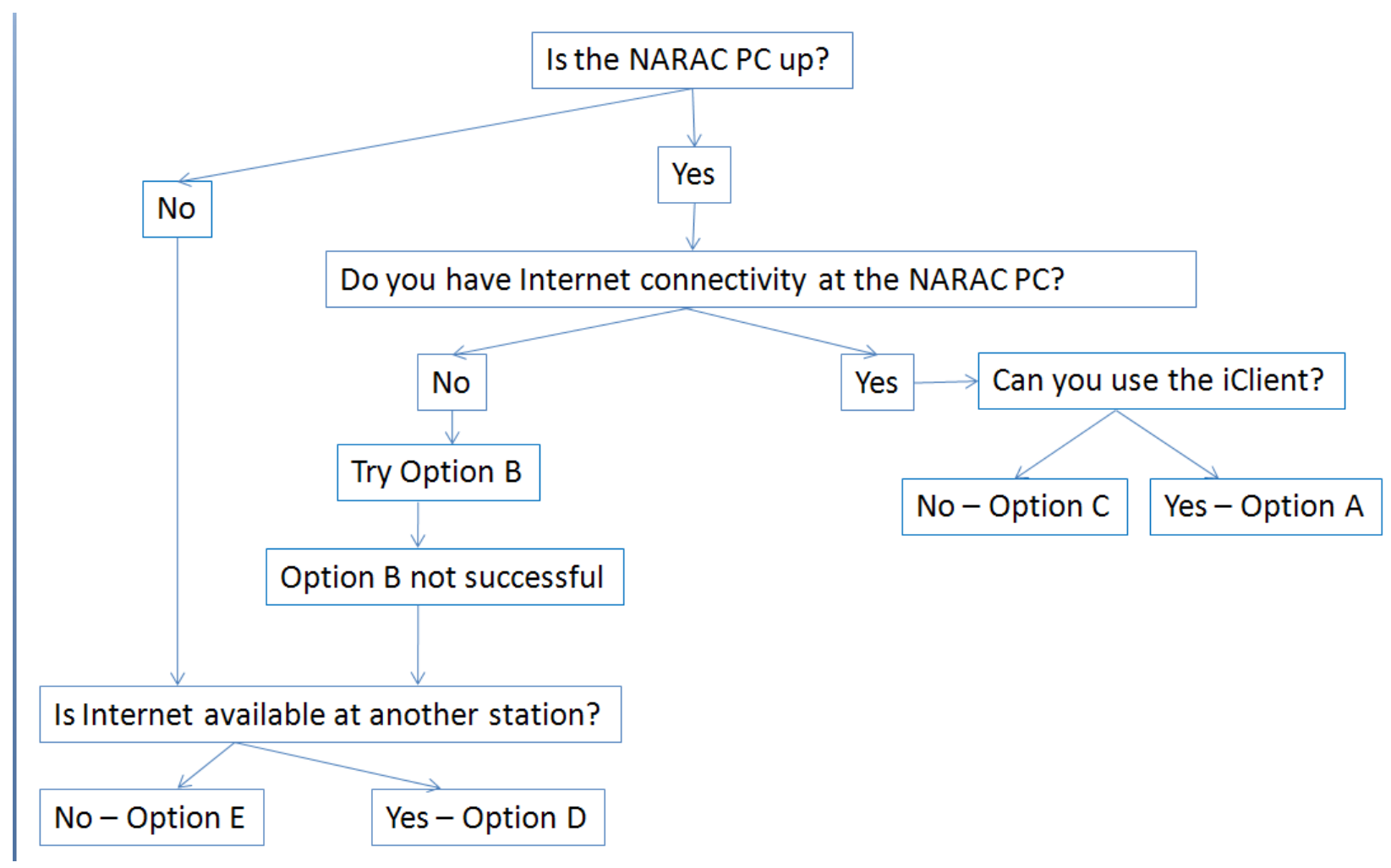

\section{Option A}

Primary (Default): iClient over Internet on NARAC PC

iClient Settings:

To maximize the iClient for Internet options be sure the System Preferences, Services option, Network Connection combination box is set to 'Cable/DSL'. See Image Below: 


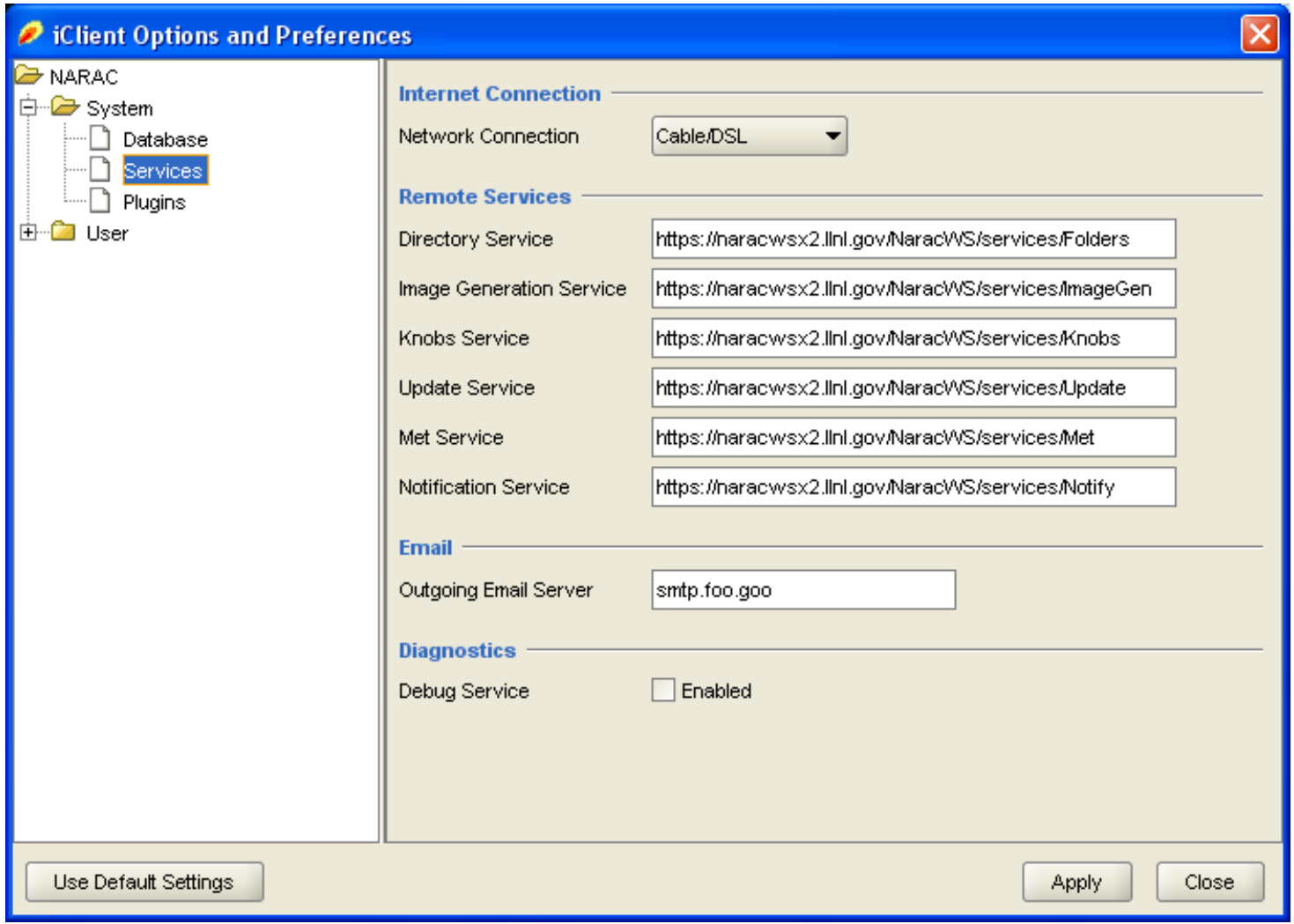

\section{Option B}

\section{Secondary: iClient over Dialup on NARAC PC}

If you lose Internet connectivity follow the following steps to get the iClient up and running:

\section{iClient Settings:}

To improve the iClient operation over a dialup modem edit the System Preferences, Services option Network Connection combination box to ‘56k Modem' (alternatively 28k Modem for very poor connections). See Image Below: 


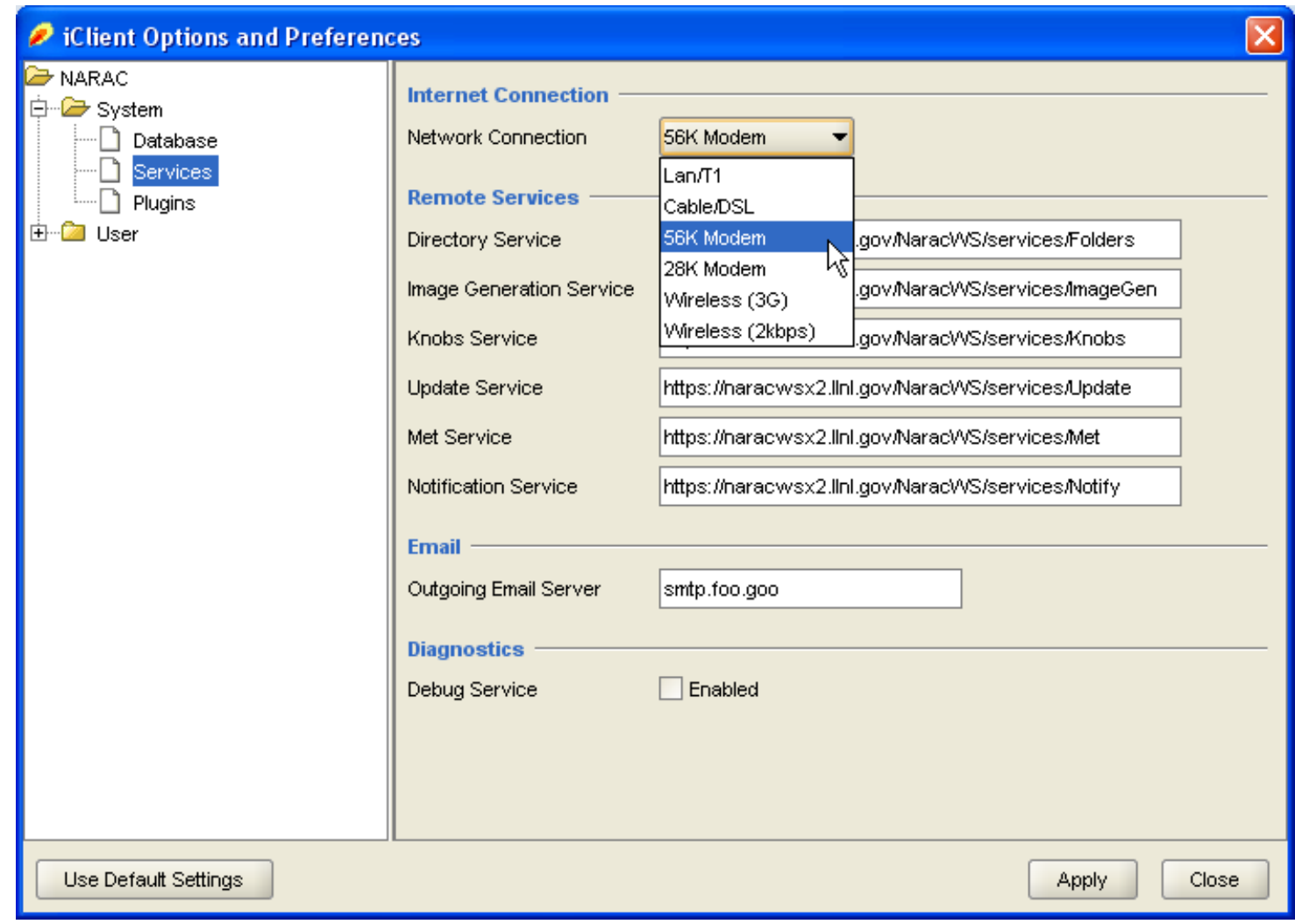

Double-click on the "Dial NARAC" shortcut on the desktop.

\section{PC Schedule Task Changes:}

If you are going to use dialup connection for an event or exercise it is important to make the following changes to the scheduled tasks on your PC. If not, the dialup connection will be interrupted every time a new meteorological data message is sent to NARAC. See Image Below.

- From the start menu select Settings -> Control Panel

- From the Control Panel select Scheduled Tasks

- Right-click on the "Datasend” task and select 'Properties'

- Unclick the "Enable” checkbox.

This will temporarily disable sending meteorological data to NARAC. For a short exercise it will not be a problem, however, if this will be disabled for some time you must notify NARAC Customer Support so that NARAC can collect your tower data. 


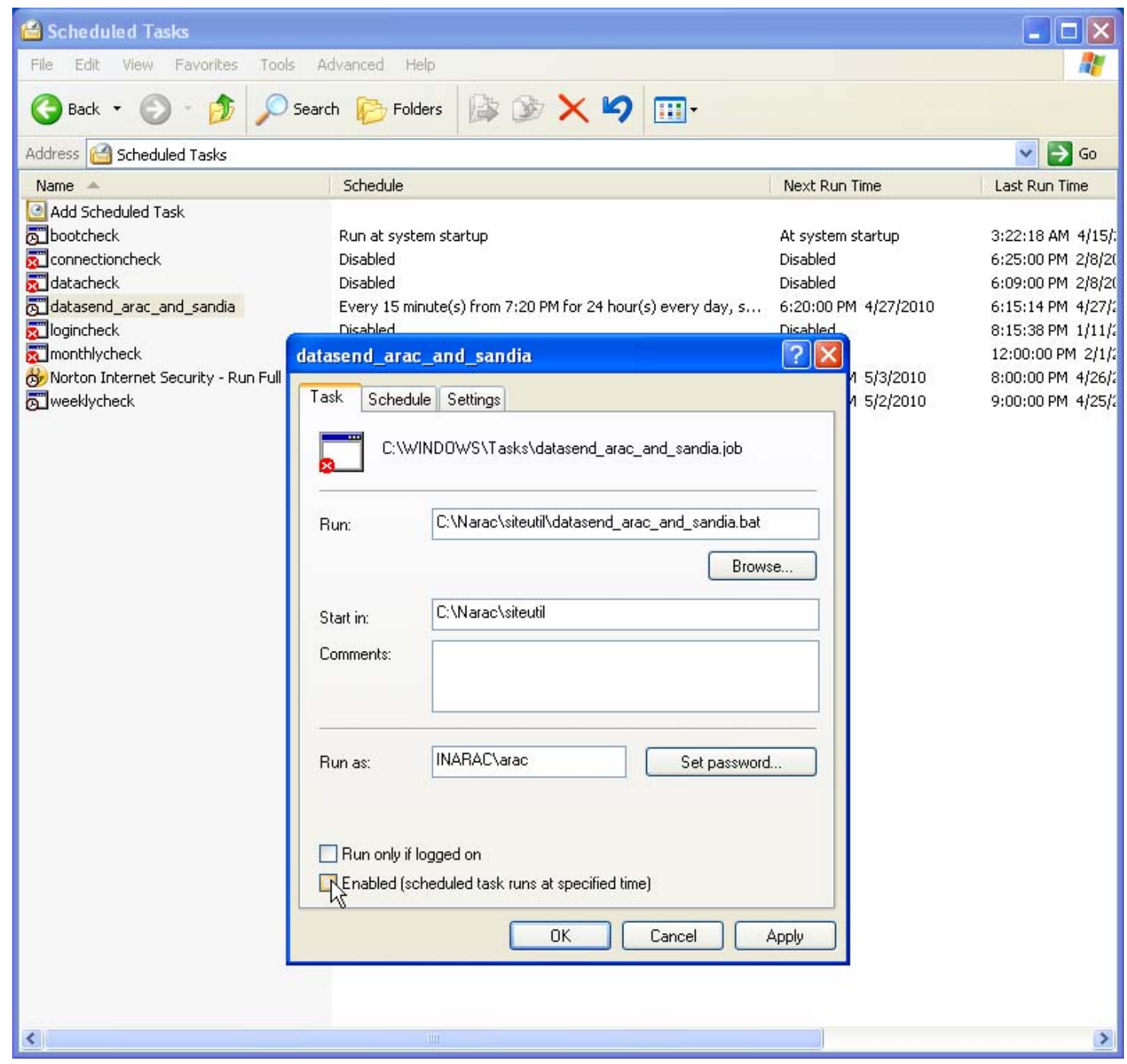

Important: When internet connection is restored, return the iClient System Preferences and Scheduled Tasks to the previous settings. Call NARAC Customer Support at 925-422-9159. 


\section{Option C}

\section{First Alternate: NARAC Web on NARAC PC (internet or dialup)}

If the iClient will not function for an exercise or event call NARAC on the emergency number and bring up NARAC Web in a web browser (go to https://naracweb.llnl.gov/web/signIn.html)

NARAC Web has all the capabilities for submitting runs to NARAC as the iClient (all the NNPP scenarios and site maps). However, measurements can only be added to a Web-created event using the preformatted spreadsheet file.

\section{Option D}

\section{Second Alternate: NARAC Web on another PC over internet}

If the NARAC PC is down and will not function for an exercise or event call NARAC on the emergency number and bring up NARAC Web in a web browser on ANY other PC with external internet (go to https://naracweb.llnl.gov/web/signIn.html).

NARAC Web has all the capabilities for submitting runs to NARAC as the iClient (all the NNPP scenarios and site maps). However, measurements can only be added to a Web-created event using the preformatted spreadsheet file.

\section{Option E}

\section{Third Alternate: Call NARAC and provide information by phone}

If the internet is completely unavailable, call NARAC at 925-422-9100. Be prepared to provide the same information to NARAC over the phone that you would normally provide via the iClient or NARAC web tools. NARAC Operations staff will do the calculation for you and fax the results to a number that you provide. 


\section{Clock Set Up}


Right click on the clock in the lower right corner:

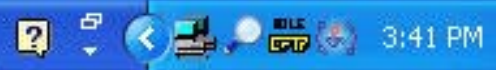

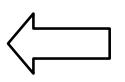

Select “Adjust Date/Time" from the menu:

\begin{tabular}{|l|}
\hline Toolbars \\
\hline Adjust Date/Time \\
\hline Customize Notifications... \\
\hline Cascade Windows \\
Tile Windows Horizontally \\
Tile Windows Vertically \\
Show the Desktop \\
\hline Task Manager \\
\hline Lock the Taskbar \\
Properties \\
\hline
\end{tabular}

On the Date and Time tab, set to GMT Standard time and date (not local time):

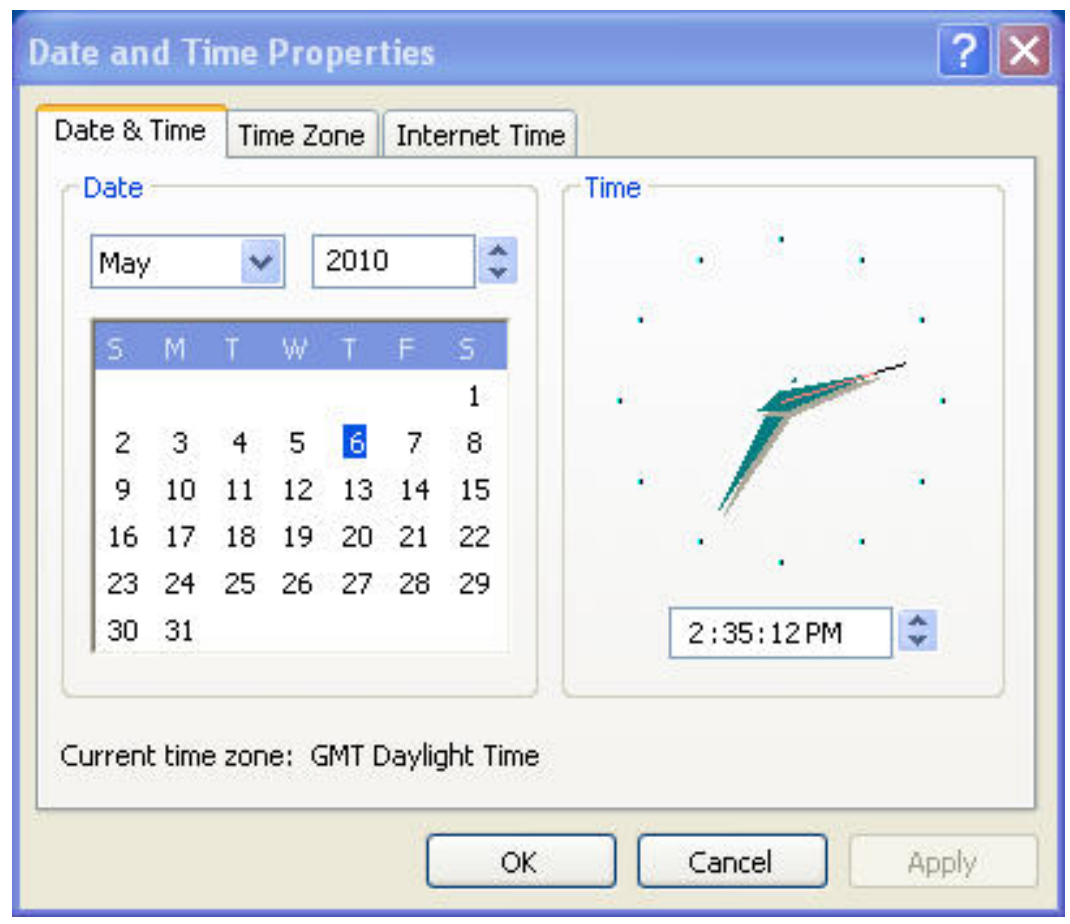

To check this you can use: http://www.worldtimeserver.com/current time in UTC.aspx 
On the Time Zone tab, select (GMT) Greenwich Mean Time: Dublin, Edinburgh, Lisbon, London and uncheck box for "Automatically adjust clock for daylight savings changes":

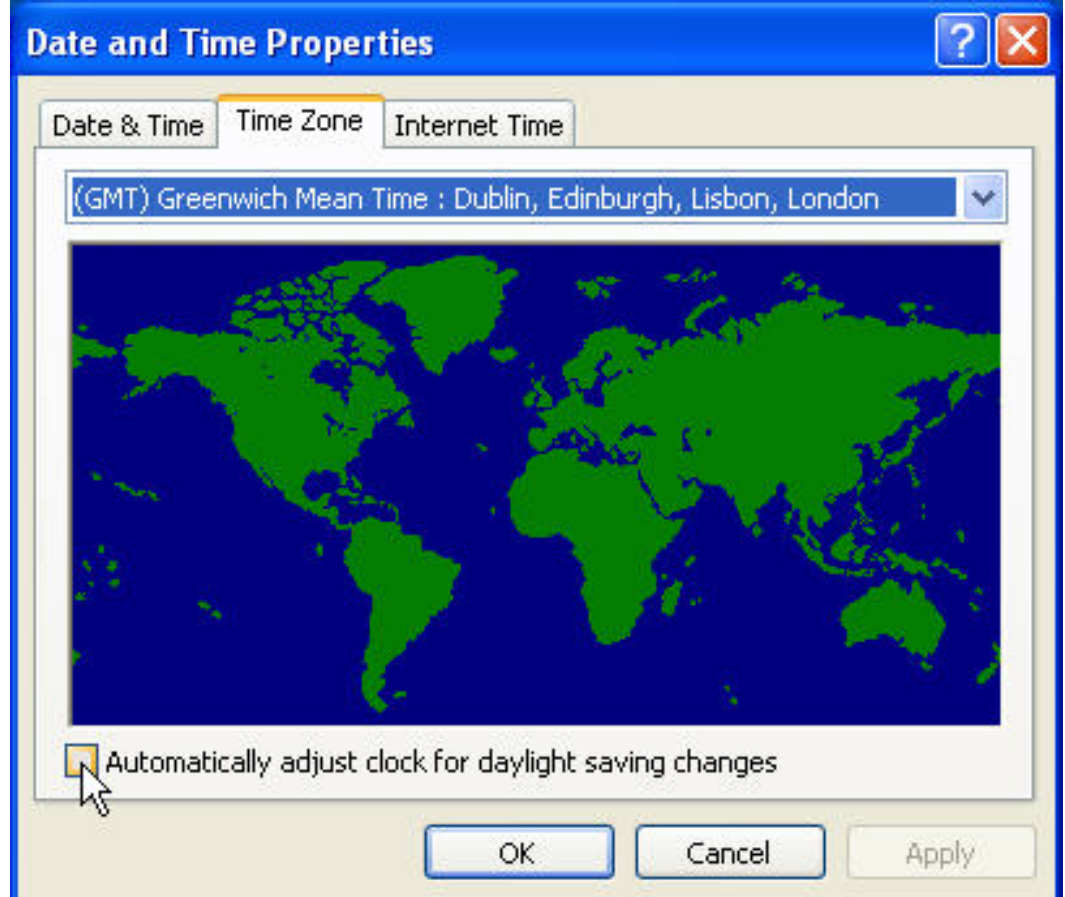

On the Internet Time tab, check the Automatically synchronize with Internet time server.

\section{Date and Time Properties}

Date \& Time Time Zone Internet Time

Automatically synchronize with an Internet time server

Server: time.nist.gov $\vee$ Update Now

The time has been successfully synchronized with time.nist.gov on

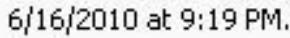

Next synchronization: $6 / 23 / 2010$ at 9:19 PM

Synchronization can occur only when your computer is connected to the Internet. Learn more about time synchronization in Help and Support Center.

OK

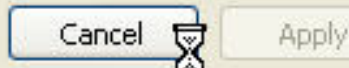

Press "Apply" if any changes were made. 